\title{
La vacunación con ALVAC y AIDSVAX no mostró niveles adecuados de protección para prevenir la infección por VIH
}

\author{
Vaccination with ALVAC and AISVAX did not show adequate protection levels to prevent HIV-1 infection
}

Rerks-Ngarm y col. N Engl J Med. 2009;361:2209-22

\section{Objetivo}

Evaluar la eficacia de un esquema de vacunación para prevenir la infección por el virus de inmunodeficiencia humana (VIH), y para reducir los niveles de viremia precoz en pacientes ya infectados.

\section{Diseño y Lugar}

Estudio aleatorizado, multicéntrico, doble ciego y controlado contra placebo. Se desarrollo en Tailandia con tres años de seguimiento (2003 a 2005).

\section{Pacientes e Intervención}

Se incluyeron 16.402 hombres y mujeres no embarazadas entre 18 y 30 años, mayormente heterosexuales, sin infección por VIH, y sin pertenencia a ningún grupo de riesgo definido. Se aleatorizó a los pacientes a recibir placebo, o cuatro dosis de vacuna ALVAC HIV (semana 0, 4, 12 y 24) y dos dosis de refuerzo con AIDSVAX (semana 12 y 24$)$.

\section{Medición de resultados principales}

Riesgo de infección por VIH y niveles de viremia precoz entre los que se infectaron en ambos grupos.

\section{Resultados principales:}

Con respecto a la prevención de la infección por VIH los principales resultados pueden verse en la Tabla 1.
La vacunación no altero los niveles de viremia, ni el recuento de CD4 en los sujetos que se infectaron.

Tabla 1: Eficacia de la vacunación de acuerdo al tipo de análisis utilizado.

\begin{tabular}{c|c|c|c} 
Tipo de Análisis & Población & $\mathbf{1 - H R}^{*}$ (IC95\%)) & P \\
\hline Por intención de tratar & 16.402 & $26,4 \%(-4,0$ a 47,9$)$ & 0,08 \\
\hline Por protocolo* & 12.542 & $26,2 \%(-13,3$ a 51,9$)$ & 0,16 \\
\hline $\begin{array}{c}\text { Por intención de tratar } \\
\text { modificado }^{\star \star}\end{array}$ & 16.395 & $31,2 \%(1,1$ a 52,1$)$ & 0,04 \\
\hline
\end{tabular}

*Pacientes que recibieron las cuatro dosis de vacuna dentro del marco de tiempo especificado. ${ }^{*}$ Se excluyeron siete pacientes que eran $\mathrm{VIH}$ positivos al momento de la aleatorización. HR=Hazard Ratio

\section{Conclusiones}

La vacunación con ALVAC-HIV y AIDSVAX B/E podría conferir un modesto beneficio en la reducción del riesgo de infección por $\mathrm{VIH}$ en una población mayoritariamente heterosexual.

Palabras claves: Vacunación VIH, eficacia, estudio aleatorizado. Keywords: HIV vaccination, efficacy, randomized trial

Fuentes de financiamiento: Sanofi Pasteur proveyó la vacuna ALVAC-HIV. Tres autores trabajaban para Sanofi.Pasteur.

Ver glosario

\section{Comentario}

Desafortunadamente los resultados de eficacia de los tres mayores estudios de vacunas contra el $\mathrm{VIH}$ realizados en humanos han fracasado ${ }^{1-3}$. En este estudio sólo se encontró un beneficio modesto a favor de la vacunación al efectuar un análisis no pre-especificado, el cual además mostró un intervalo de confianza muy amplio. Es importante recordar que la población de este estudio pertenecía mayoritariamente a grupos de bajo $(47,5 \%)$ y mediano $(28,4 \%)$ riesgo de infección. Los resultados podrían haber sido distintos en una población de mayor riesgo. Contamos en la actualidad con medidas efectivas para prevenir la transmisión: uso de preservativo, programas de provisión de agujas en adictos endovenosos, tratamiento de las embarazadas VIH (+) para prevención de transmisión vertical.

Sin embargo, a pesar de su eficacia a nivel individual, estas no siempre tienen el mismo impacto a nivel comunitario. Otras medidas preventivas como la circunsición, los microbicidas, el uso de drogas (tenofovir) en la profilaxis pre-exposición, y el tratamiento precoz de las personas infectadas, están siendo evaluadas; algunas con resultados alentadores. La circuncisión masculina demostró recientemente en tres estudios aleatoriza$\operatorname{dos}^{4 \cdot 6}$ una reducción del riesgo de infección del $60 \%$ en hombres heterosexuales. El tratamiento antirretroviral precoz de las personas infectadas también reduce el riesgo de infección de su pareja ${ }^{7,8}$.

El desarrollo de una vacuna inmunogénica, segura y eficaz en la prevención de la infección por este virus requerirá de una mejor comprensión de los mecanismos iniciales de la infección y del tipo de respuesta inmune involucrada.

\section{Conclusiones de la comentadora}

Si bien esta vacuna no mostró resultados que la hagan apta para ser implementada dentro de los programas de prevención masivos, abre el camino para nuevas líneas de investigación.

Mara Huberman [ Médica Infectóloga del Centro de estudios infectológicos Dr. Daniel Stamboulian y de Helios Salud. marahuberman@ hotmail.com ]

Huberman M. La vacunacion con ALVAC y AIDSVAX para prevenir la infección por VIH no mostró niveles adecuados de protección. Evid. actual. práct. ambul; 13 (2):45, Abr-Jun.2010. Comentado de: S Rerks-Ngarm y col. Vaccination with ALVAC and AIDSVAX to prevent HIV-1 infection in Thailand. N Engl J Med.2009;361:2209-22. PMID 19843557.

\section{Referencias}

1. Pitisuttithum $P$, y col. Randomized, double blind placebo-controlled efficacy trial of a bivalent recombinant glycoprotein 120 HIV 1 vaccine among injection drug users in Bangkok, Thailand J Infect Dis 2006; 194:1661-1671

2. Flynn NM, y col. Placebo-controlled phase 3 trial of recombinant glycoprotein 120 vaccine to prevent HIV1 infection. J Infect Dis 2005;191:654-65

3. Buchbinder SP, y col. Efficacy assessment of a cell-mediated immunity HIV-1 vaccine (the Step study):a double blind, randomised placebo-controlled test of concept trial. Lancet 2008;372:1881-93

4. Bailey RC, y col. Male circumcision for HIV prevention in young men in kisumu, Kenya: a randomized control trial. Lancet 2007;369:643-656

5. Auvert B, y col. Randomized controlled intervention trial of male circumcision for reduction of HIV risk: the ANRS 1265 trial Plos Med 2005;2e298.

6. Gray RH, y col. Male circumcision for HIV prevention in Rakai Uganda: a randomized trial. Lancet 2007;369:657-666

7. Quinn TC, y col. Viral load and heterosexual transmission of human immunodeficiency virus type 1. N Engl J Med 2000;342:921-929

8. Bunnell R, y col. Changes in sexual behaviour and risk of HIV transmission after antiretroviral therapy and prevention interventions in rural Uganda. AIDS 2006;20:85-92 